\title{
- News \& Views•
}

\section{The 2020/21 Extremely Cold Winter in China Influenced by the Synergistic Effect of La Niña and Warm Arctic*}

\author{
Fei ZHENG ${ }^{* 1,2}$, Yuan YUAN*3, Yihui DING ${ }^{3}$, Kexin LI $^{1,4}$, Xianghui FANG ${ }^{5}$, Yuheng ZHAO ${ }^{3}$, \\ Yue SUN1 ${ }^{1}$, Jiang ZHU ${ }^{1,4}$, Zongjian $\mathrm{KE}^{3}$, Ji WANG ${ }^{6}$, and Xiaolong JIA ${ }^{3}$ \\ ${ }^{1}$ International Center for Climate and Environment Science (ICCES), Institute of Atmospheric Physics, \\ Chinese Academy of Sciences, Beijing 100029, China \\ ${ }^{2}$ Collaborative Innovation Center on Forecast and Evaluation of Meteorological Disasters, \\ Nanjing University of Information Science \& Technology, Nanjing 210044, China \\ ${ }^{3}$ National Climate Center, Beijing 100081, China \\ ${ }^{4}$ University of Chinese Academy of Sciences, Beijing 100049, China \\ ${ }^{5}$ Department of Atmospheric and Oceanic Sciences \& Institute of Atmospheric Sciences, \\ Fudan University, Shanghai 200438, China \\ ${ }^{6}$ Beijing Municipal Climate Center, Beijing 100089, China
}

(Received 19 January 2021; revised 31 January 2021; accepted 1 February 2021)

\begin{abstract}
In the first half of winter 2020/21, China has experienced an extremely cold period across both northern and southern regions, with record-breaking low temperatures set in many stations of China. Meanwhile, a moderate La Niña event which exceeded both oceanic and atmospheric thresholds began in August 2020 and in a few months developed into its mature phase, just prior to the 2020/21 winter. In this report, the mid-high-latitude large-scale atmospheric circulation anomalies in the Northern Hemisphere, which were forced by the negative phase of Arctic Oscillation, a strengthened Siberian High, an intensified Ural High and a deepened East Asian Trough, are considered to be the direct reason for the frequent cold surges in winter 2020/21. At the same time, the synergistic effect of the warm Arctic and the cold tropical Pacific (La Niña) provided an indispensable background, at a hemispheric scale, to intensify the atmospheric circulation anomalies in middleto-high latitudes. In the end, a most recent La Niña prediction is provided and the on-coming evolution of climate is discussed for the remaining part of the 2020/21 winter for the purpose of future decision-making and early warning.
\end{abstract}

Key words: extremely cold winter, anomalous atmospheric circulation, synergistic effect, La Niña, warm Arctic

Citation: Zheng, F., and Coauthors, 2022: The 2020/21 extremely cold winter in China influenced by the synergistic effect of La Niña and warm Arctic. Adv. Atmos. Sci., 39(4), 546-552, https://doi.org/10.1007/s00376-021-1033-y.

During the first half part of winter 2020/21, mainly from 1st December 2020 to 10th January 2021, China has experienced three strong cold air processes with two cold surges invading from the northern into the southern regions. During this period, three cold air outbreaks occurred in China on 13th-15th December 2020, 29th December 2020-1st January 2021 (cold surge), and 6th-8th January 2021 (cold surge), respectively. Persistently low temperatures were reported in most parts of China, and the areas with cumulative daily mean temperature drops of over $8^{\circ} \mathrm{C}$ occupied $1.42,2.82$, and 0.44 million square kilometers, respectively. Therefore, the average temperature during this time period (1st December 2020-10th January 2021) was about $1{ }^{\circ} \mathrm{C}-2^{\circ} \mathrm{C}$ below normal in most of China, with the exception of the Tibetan Plateau. In parts of northern and southern China, the average temperature anomalies were even as low as $-4^{\circ} \mathrm{C}$ (Fig. 1). Affected by these strong cold air processes, the daily minimum temperatures of at least 405 national stations reached the extreme event monitoring standard. These stations were mainly located in North China, northeast of Huanghuai, east of Jianghuai, the middle and lower reaches of Yangtze River, and in the eastern part of Northwest China. In Inner Mongolia, Hebei, Jiangsu, Shanghai,

※ This paper is a contribution to the special issue on Extreme Cold Events from East Asia to North America in Winter 2020/21.

* Corresponding authors: Fei ZHENG, Yuan YUAN

Email: zhengfei@mail.iap.ac.cn, yuany@cma.gov.cn 


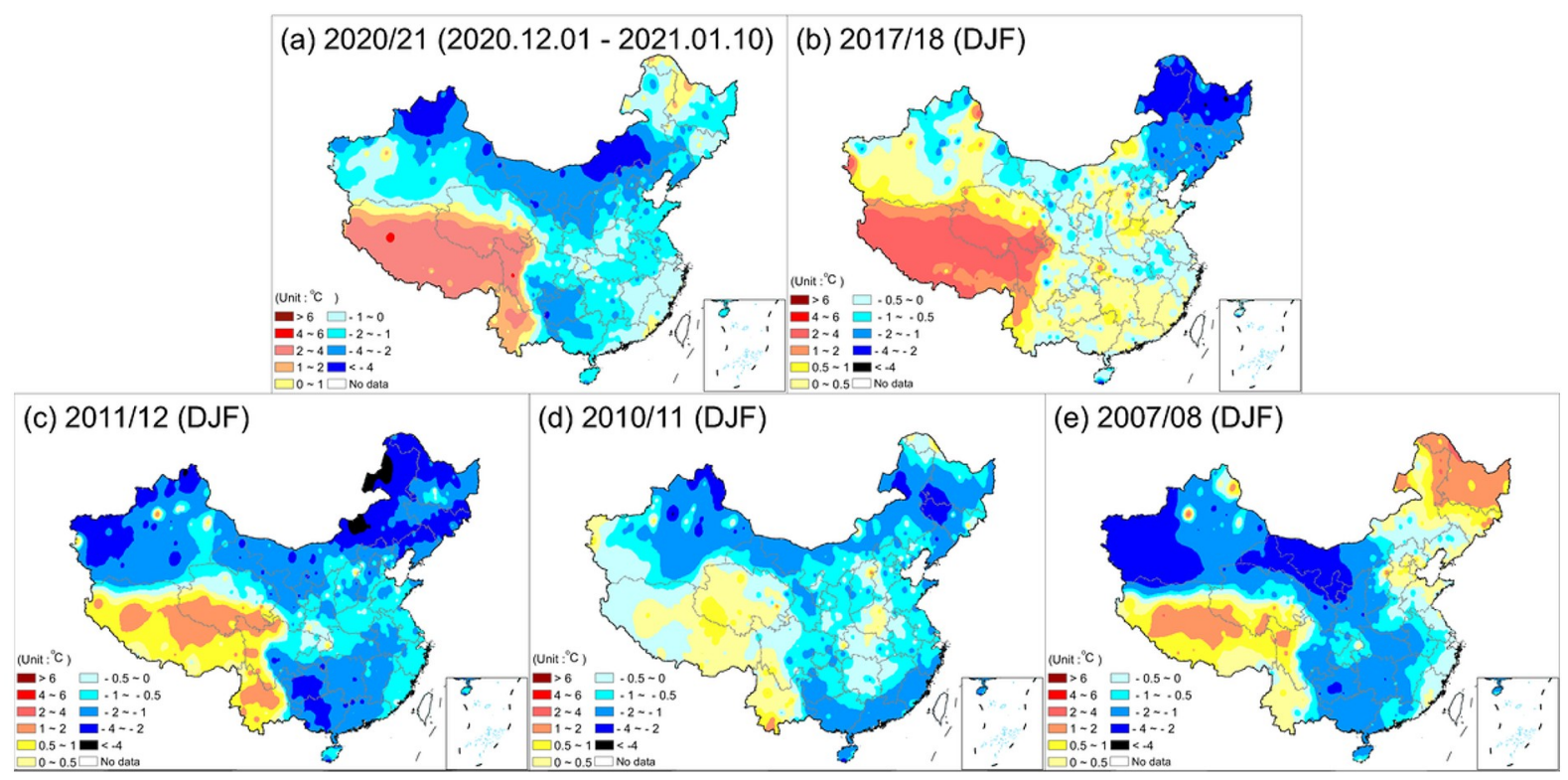

Fig. 1. Winter (DJF) averaged temperature anomalies in China for recent five La Niña events. (a) 2020/21 (1st Dec-10th Jan), (b) 2017/18, (c) 2011/12, (d) 2010/11, (e) 2007/08.

and other provinces, the lowest temperature in 58 cities (counties) either broke records or reached historical extreme values since the stations were established. These cities included Beijing, Shanghai, Nanjing, Hangzhou, Hefei, and Wuhan, among others.

Accordingly, the large-scale atmospheric circulation anomalies that were in place included: a negative phase of Arctic Oscillation (AO), an intensified Ural High, and an East Asian Trough. The combination of these factors directly contributed to the extremely cold conditions observed in most parts of China. During this period, the AO has changed from a positive phase to a negative phase since 1st December 2020 and lasted until mid-January 2021. The Siberian High was greatly intensified and the meridional geopotential height gradient over the mid-high latitudes was largely increased, with positive anomalies of 500-hPa geopotential heights over the North Pole and to the east of Europe and negative anomalies over northern East Asia (Figs. 2a and b). As a result, the combined effects of an intensified Ural High and deepened East Asian Trough led to strong cold air transport processes invading China. More importantly, such an anomalous circulation pattern showed a strong persistence from 1st December 2020 to 10th Jan 2021, which included the negative AO phase (Fig. 2c), the stronger meridional geopotential height gradient, and the intensified Siberian High (Fig. 2d). This was especially true during the period from late December 2020 to mid-Jan 2021, when the two cold surges occurred in China. During this time, the negative AO decreased below one standard deviation and the intensity of Siberian High increased above one standard deviation persistently (Figs. 2c and 2d).

Over the Arctic region it was warmer. Arctic warming has been widely recognized for a long time (e.g., Manabe and Wetherald, 1975; Maykut, 1982; Taylor et al., 2018; Cohen et al., 2020). This process is supported through the high sensitivity of sea ice and snow cover to external heat sources and the feedback effect of the related albedo. Interestingly, the Arctic region has become one of the most rapidly warming regions in the world and its annual average warming rate has reached 6-7 times the global average, which is called Arctic Amplification (AA; e.g., Cohen et al., 2014; Huang et al., 2017b). According to NOAA's 15th annual Arctic Report Card, October 2019-September 2020 represented the second warmest 12month period of observed surface air temperatures over Arctic land during the last century (Ballinger, et al., 2020). Accompanied by AA, Arctic sea ice is drastically reduced. During the autumn in 2020, the Arctic sea ice extent has reached the second-lowest level in September 2020 since 1979 (https://nsidc.org/arcticseaicenews/), which can significantly strengthen and reinforce the presence of the Siberian high, as observed during the 2020/21 winter (Wu and Wang, 2002; Wu et al. 2011a). And this effect was also enhanced by the typical negative Arctic Dipole (AD) wind pattern in the summer of 2020 (Wu et al. 2016), which ranked as the lowest since 1979 (figure not shown).

La Niña, also known as the cold phase of ENSO (El Niño-Southern Oscillation), is a cool ocean state that develops over the central to eastern equatorial Pacific which sometimes follows an El Niño but causes nearly the opposite extreme climate effects (e.g., Chen et al., 2013). Essentially, the displacement of atmospheric and global wind cycle circulation observed during La Niña contributes to extensive changes in temperatures and weather around the world (e.g., Hu et al., 2014; Zheng et al., 2015). For example, under the influence of 2007/08 La Niña event, South China experienced a severe snow and ice storm during Jan-Feb 2008 (i.e., the mature phase of La Niña), which had exerted serious impacts on traffic, 
(a) $500 \mathrm{hPa}$ HGT anomaly

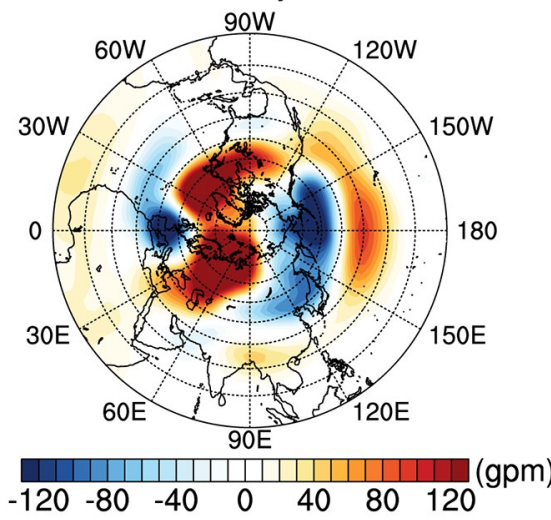

(c) Daily $\mathrm{AO}$ index

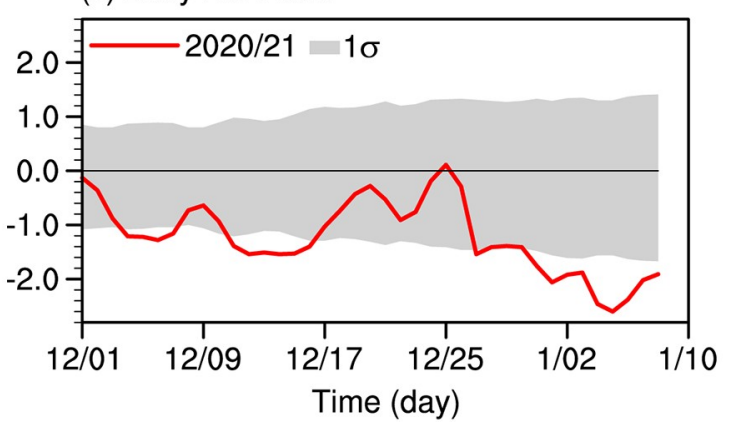

(b) SLP anomaly

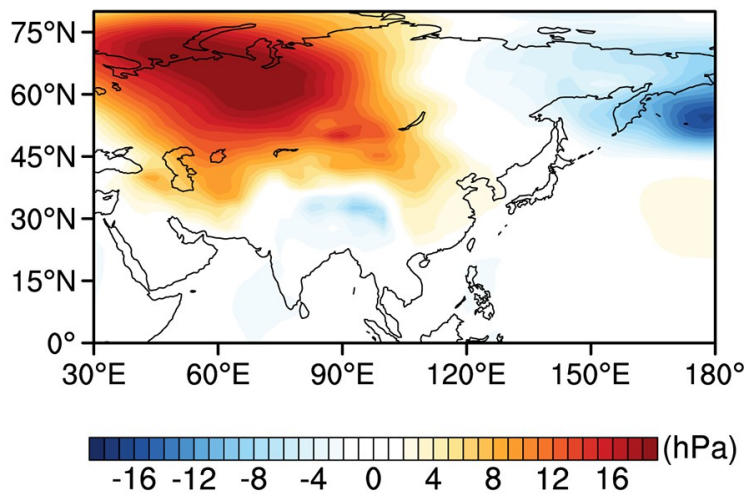

(d) Daily Siberian High index

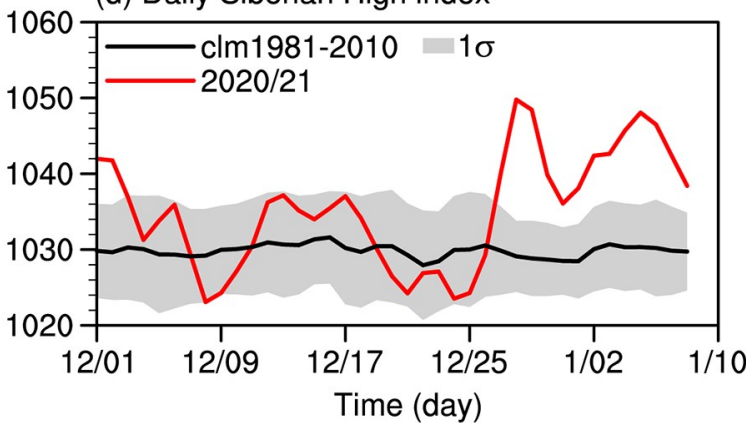

Fig. 2. Middle-high-latitude atmospheric circulation anomalies in the Northern Hemisphere from 1st December 2020 to 10th January 2021. (a) $500 \mathrm{hPa}$ geopotential height, (b) sea level pressure, (c) daily Arctic Oscillation index, and (d) daily Siberian High index (1st December 2020 to 8th January 2021).

electricity, agriculture, mass production, and life (e.g. Ding et al., 2008; Gao, 2009; Wu et al., 2011b; Yuan and Yan, 2013).

The 2020/21 La Niña event started in August 2020 (i.e., the Niño-3.4 index exceed $-0.5^{\circ} \mathrm{C}$ ) and continued to gain strength into autumn (i.e., September-October-November, SON, 2020) before approaching its peak in the Northern Hemisphere winter (i.e., December-January-February, DJF). During these last three months, the Niño-3.4 SST anomaly over the tropical Pacific was much cooler than the La Niña threshold of $-0.5^{\circ} \mathrm{C}$, and has been lower than $-1.0^{\circ} \mathrm{C}$ since October 2020, according to the ERSST v5 dataset (Huang et al., 2017a). Various GODAS and NCEP reanalysis data (Behringer and Xue, 2004) involving the atmospheric and oceanic processes responsible for the onset and development of the 2020/21 La Niña event are utilized to illustrate their coherent relationships. Figure 3 shows the temporal evolutions of the interannual variations in SST, $850 \mathrm{hPa}$ zonal wind, $850 \mathrm{hPa}$ meridional wind, and thermocline depth in the equatorial Pacific in 2020. The development of the 2020/21 La Niña event is quite clear at the equator, and there is a close relationship among these anomalous fields. The predominance of the anomalous southeasterly winds over the central equatorial region from January to April in 2020 has essentially prevented the enhancement of the observed westerly winds over the warm pool (Figs. 3a and b). A subsequent easterly wind burst in the lower atmosphere further initiated an oceanic upwelling Kelvin wave which served to be a facilitator of the 2020/21 La Niña condition. Forced by the upwelling Kelvin wave, cold water accumulated in the warm pool and started to propagate eastward, resulting in a shoaling of the thermocline and a net cooling of the subsurface layers in the eastern equatorial Pacific (Fig. 3d). These SST anomalies became increasingly negative during the entire summer of 2020 after the subsurface cold water reached the eastern tropical Pacific surface (Fig. 3c). The accumulated cold water in the eastern Pacific became more pronounced and caused the SST anomalies to get colder across the eastern to central equatorial Pacific. This was thought to be triggered by enhanced easterly trade winds that were observed over most of the equatorial Pacific, and the weak La Niña condition gradually strengthened to attain moderate intensity during autumn 2020.

This moderate La Niña event also contributed to the impact of Arctic air on the winter climate in East Asia. From a planetary scale, the combination of warm temperature anomalies in Arctic region and cold temperature anomalies in the tropical ocean largely reduced the Equator-Arctic temperature gradient and further provided for a favorable background state for the cold conditions observed in China during the first half of winter 2020/21. This process intensified the meridional height gradient over the mid-high latitudes in winter, leading to a stronger ridge over the Ural, an enhanced East Asian Trough over Japan, and a more northward subtropical westerly jet over East Asia (e.g., Liu and Ding, 1992; Huang and 
(a) $850-\mathrm{hPa} \mathrm{U}$

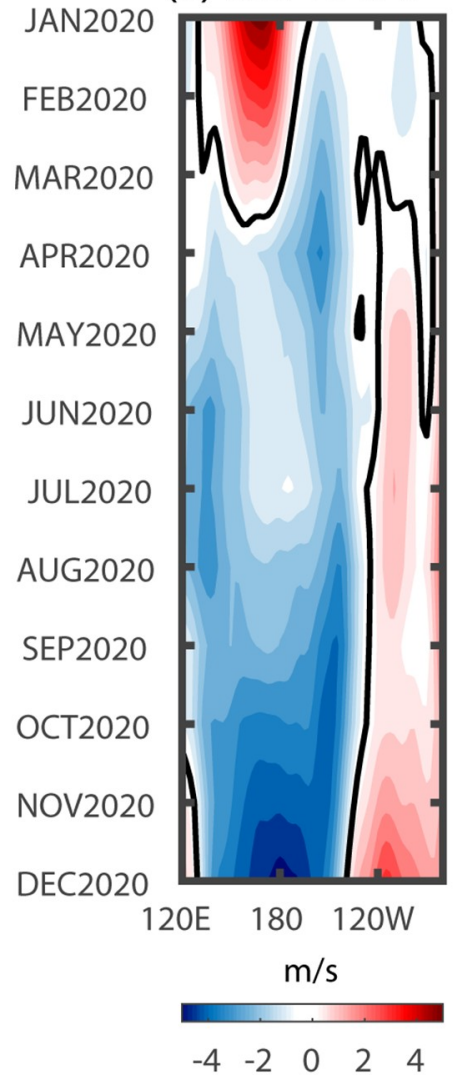

(b) $850-\mathrm{hPa} \mathrm{V}$

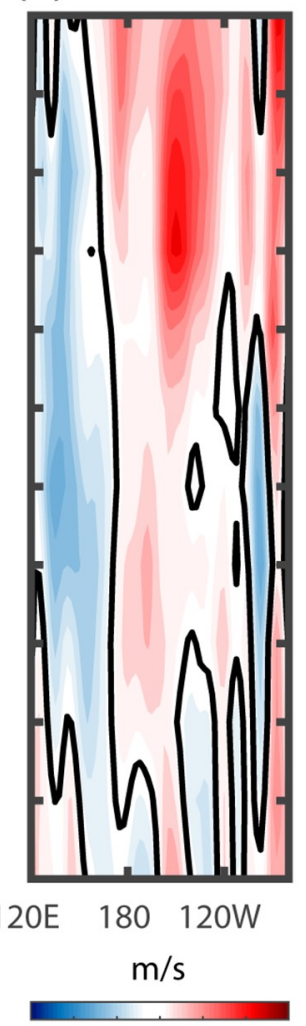

$\begin{array}{lllllll}-3 & -2 & -1 & 0 & 1 & 2 & 3\end{array}$ (c) SST

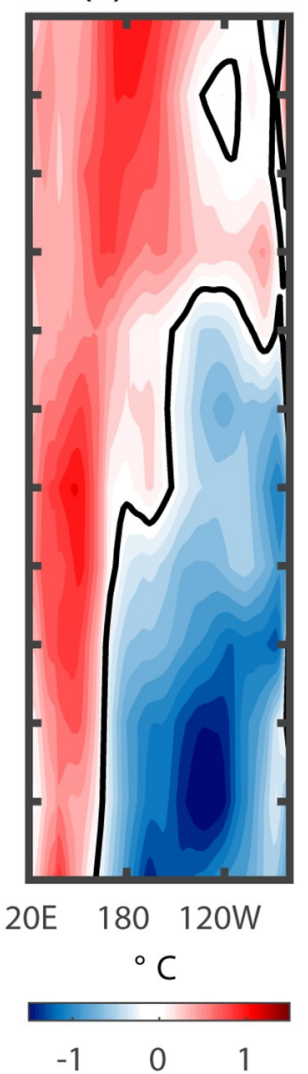

(d) TCD

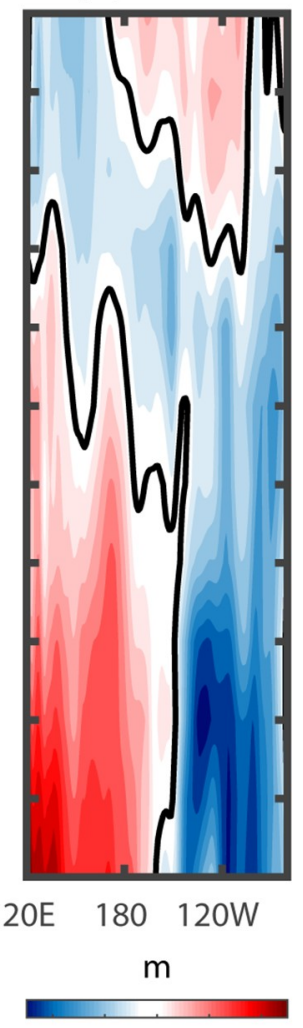

$-20-10 \quad 0 \quad 1020$

Fig. 3. Temporal evolutions of interannual anomalies along the equatorial Pacific (averaged between $5^{\circ} \mathrm{S}$ and $5^{\circ} \mathrm{N}$ ) in 2020 for (a) $850 \mathrm{hPa}$ zonal wind, (b) $850 \mathrm{hPa}$ meridional wind, (c) SST, and (d) thermocline depth (TCD). The unit is $\mathrm{m} \mathrm{s}^{-1}$ in (a) and (b), ${ }^{\circ} \mathrm{C}$ in (c), and $\mathrm{m}$ in (d).

Chen, 2002; Yang et al., 2002; Zhang et al., 2008). This pattern favors a cold winter for most parts of East Asia, with snow and ice events expected in southern China during the La Niña mature Phase (e.g., Ding et al., 2008; Gao, 2009; Wu et al., 2011a; Yuan et al., 2014). Cold winter cases have been observed in five recent La Niña events (Figs. 1b to e), although the cold conditions did not always occur during the first half of winter.

Moreover, from the perspective of interannual variability, Table 1 lists all La Niña events which occurred during 1980-2020, along with their strength, the Arctic sea ice extent in September, the AD pattern in summer, and the DJF averaged temperature anomaly in China, respectively. It shows clearly that not all La Niña events lead to a cold winter in China, and not all La Niña events are accompanied by reduced Arctic sea ice extent in September or by AD negative pattern in summer. Among all these La Niña events, only three cases are particularly similar to this year: 1995, 2007, and 2011. Together with 2020, they all displayed similar developing characteristics of La Niña (including the strength and SST pattern, figures not shown), reduced Arctic sea ice extent in September, and a typical AD negative pattern in summer.

It should be noted that in the context of global warming, the variations of weather and climate tend not to be slightly abnormal when swinging around the average value, but tend to deviate farther and farther from the average state, with larger and larger amplitudes. The assessment report of the Intergovernmental Panel on Climate Change (IPCC) shows that global warming has led to an increase in the frequency and intensity of extreme weather and climate events in some regions, such as extreme high-temperature events and extreme precipitation events, as well as AA. Frequent extreme cold events are also a typical response to global warming, an example being the observed cold condition during the first half of winter 2020/21, and some other similar cases of cold surge observed in both January 2016 and January 2018 (Wang et al., 2020). As described above, over the past several months, the synergistic effect of the warm Arctic (i.e., mostly induced by global warming) and the cold tropical Pacific (i.e., La Niña, the cold phase of ENSO) brought an indispensable background for the anomalous meridional, hemispheric-scale temperature gradient in the Northern Hemisphere to intensify the intrusions of cold air from polar regions into mid-high latitudes (Li et al., 2019), which further influenced the cold conditions in China during the first half of winter 2020/21. This was accompanied by intra-seasonal activities of the anomalous atmospheric circulation, such as the enhanced Siberian High, the intensified Ural High and the deepened East Asian Trough (Fig. 4). 
Table 1. La Niña events during 1980-2020 with their strength, Arctic sea ice extent in September, AD winter pattern in summer, and winter (DJF) averaged temperature anomalies in China. The row with bold font represents similar developing characteristics of La Niña, reduced Arctic sea ice extent in September, and a typical AD negative pattern in summer.

\begin{tabular}{ccccc}
\hline $\begin{array}{c}\text { La Niña events } \\
\text { (First year) }\end{array}$ & $\begin{array}{c}\text { La Niña } \\
\text { strength }\end{array}$ & $\begin{array}{c}\text { Arctic Sea Ice } \\
\text { extent in Sept }\end{array}$ & $\begin{array}{c}\text { AD pattern } \\
\text { in summer }\end{array}$ & $\begin{array}{c}\text { (DJF Ave.) Temp. } \\
\text { Anom. in China }\end{array}$ \\
\hline 1983 & week & near normal & negative & -1.6 \\
1984 & week & below normal & positive & -1.53 \\
1988 & strong & above normal & positive & 0.16 \\
$\mathbf{1 9 9 5}$ & week & below normal & negative & $\mathbf{- 0 . 5 6}$ \\
1998 & week & above normal & positive & 1.52 \\
1999 & moderate & near normal & negative & -0.53 \\
2000 & week & above normal & positive & 0.3 \\
2005 & week & near normal & negative & 0.1 \\
$\mathbf{2 0 0 7}$ & moderate & below normal & negative & $\mathbf{- 0 . 6 7}$ \\
2010 & moderate & below normal & positive & -0.69 \\
$\mathbf{2 0 1 1}$ & week & below normal & negative & $\mathbf{- 1 . 0 3}$ \\
2017 & week & above normal & positive & 0.12 \\
$\mathbf{2 0 2 0}$ & boderate & below normal & negative & $\mathbf{- 1 . 0 3}$ (1st Dec-10th Jan) \\
\hline
\end{tabular}

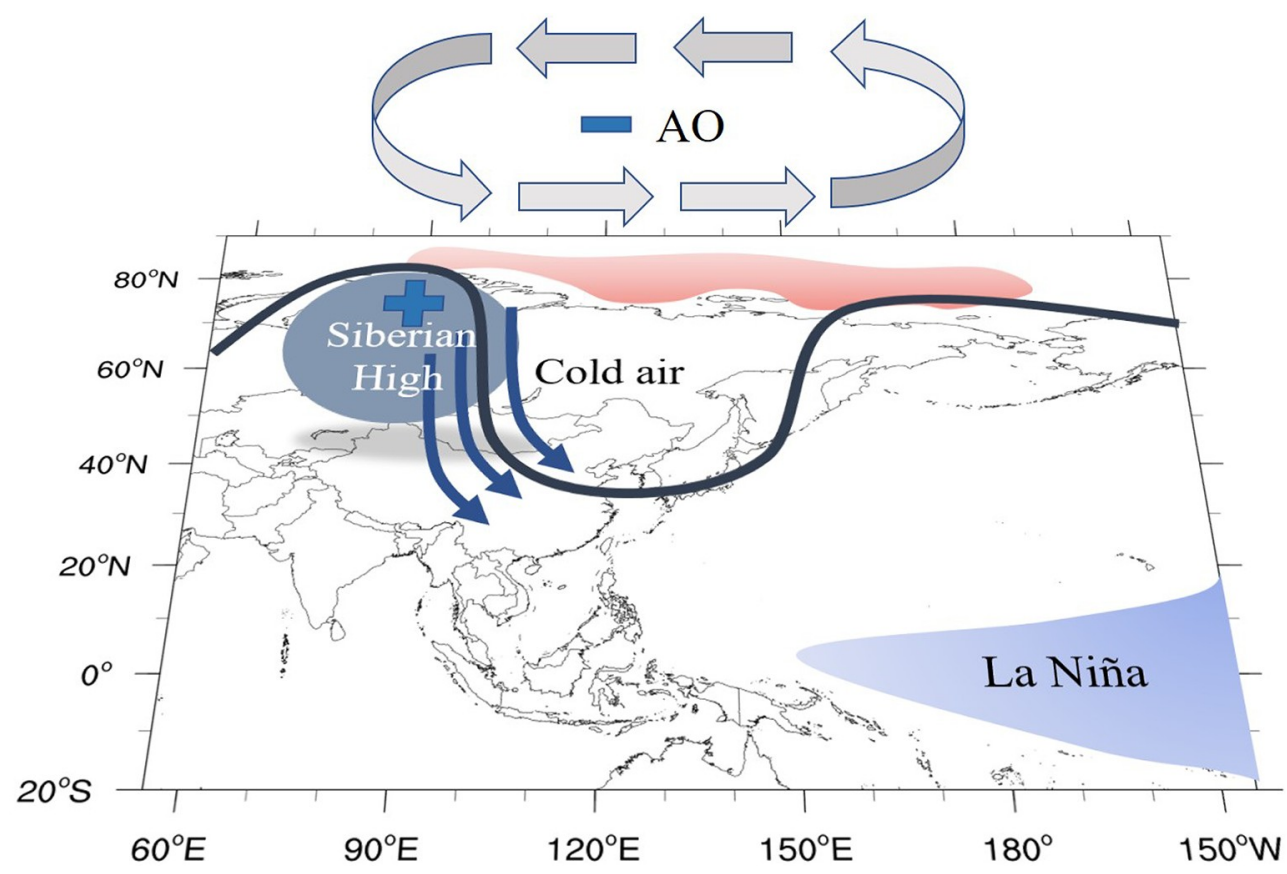

Fig. 4. A mechanism diagram on showing the process of cold air invading China as forced by the middle-high-latitude large-scale atmospheric circulation anomalies, under the synergistic effect of the warm Arctic and the cold tropical Pacific (La Niña).

Before the end of this report, we further use the ensemble prediction system (EPS) developed at the Institute of Atmospheric Physics (IAP), Chinese Academy of Sciences (Zheng et al., 2006, 2007, 2009; Zheng and Zhu, 2010, 2016; Zheng and $\mathrm{Yu}, 2017$ ), to predict the following evolution of the 2020/21 La Niña event (Fig. 5). The performance of the prediction system is documented in Zheng and Zhu (2016), in which a 20-year retrospective forecast comparison shows that good forecast skill of the EPS with a prediction lead time of up to one year is possible. The most recent ensemble forecast suggests that there is at least a 95\% chance that La Niña will persist through the 2020/21 winter, with a potential transition to ENSONeutral during spring 2021 ( $\sim 50 \%$ chance). However, it is important to note that El Niño and La Niña are not the only factors that drive global and regional climate patterns. No two La Niña events are alike, and their effects on regional climates can vary depending on the time of year and other factors as we have demonstrated in this report. In this report, the synergistic effect of both the La Niña and the warm Arctic upon the cold winter in China is only explored and illustrated relative to the 2020/21 case. Future work on employing the synergistic diagnosis approach proposed by Li et al. (2019) can fur- 

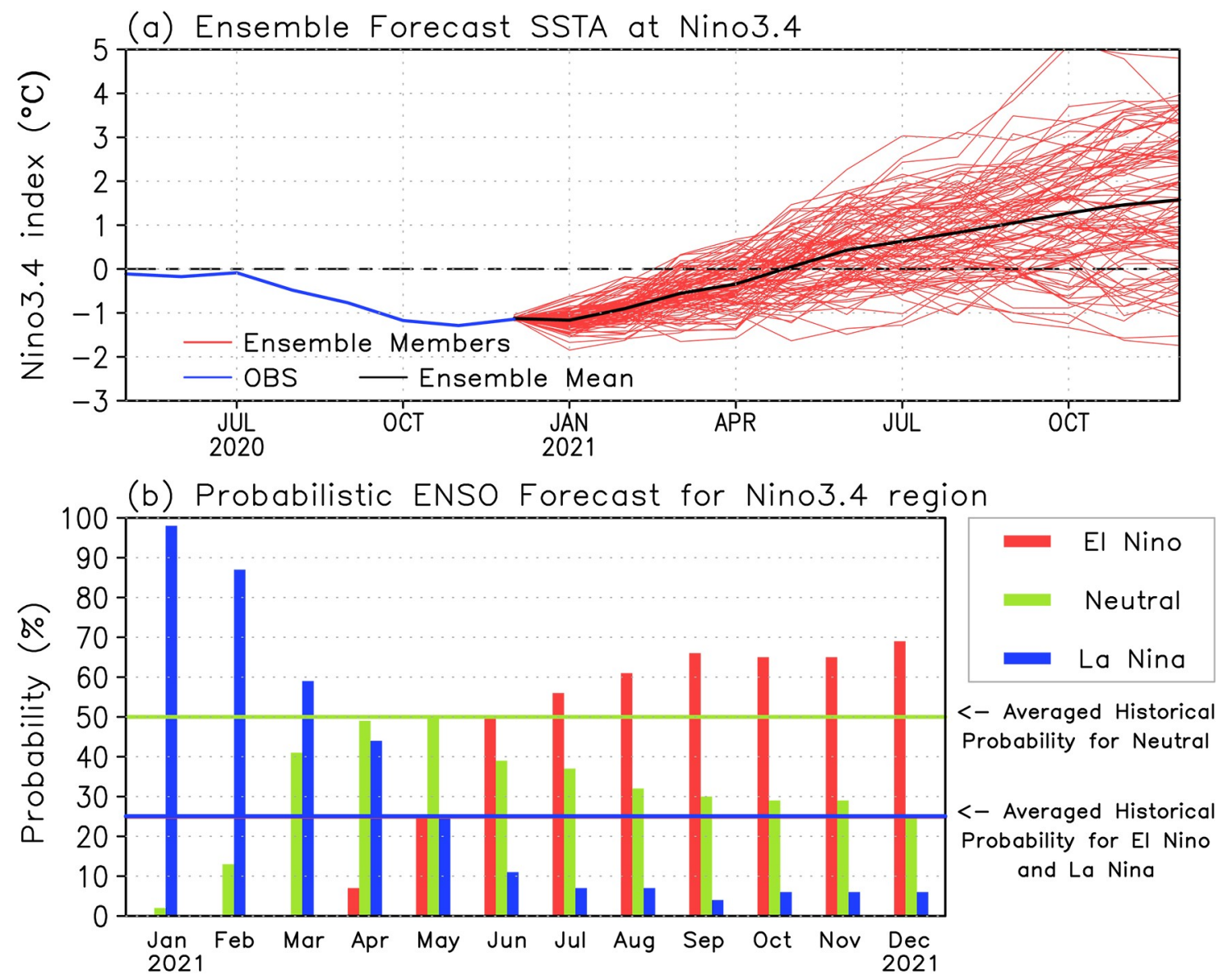

Fig. 5. Ensemble ENSO forecast started from Jan 2021 by the IAP EPS: (a) Forecasted Nino3.4 index with 100 ensemble members, and the black line represents the ensemble-mean forecast. (b) Probabilistic ENSO Forecast: The red cylinder represents the probability of occurrence of an El Niño event, the blue cylinder represents the probability of occurrence of a La Niña event, and the green cylinder represents the probability of occurrence of a neutral event. The statistical result is based on the 100-member ensemble forecast.

ther demonstrate the importance of this synergistic effect in a universal sense.

How the future climate will evolve in the remaining part of winter is still subject to some uncertainty, and people should focus on the medium-term numerical weather forecasts and the latest sub-seasonal-to-seasonal prediction for atmospheric circulations to obtain the necessary date information and early warnings. We still need to pay attention to the possible large temperature fluctuations and increased snow and rainfall in China during the late winter.

Acknowledgements. This work was supported by the national key R\&D Program of China (Grant No 2018YFC1505603), the Key Research Program of Frontier Sciences, CAS (Grant No. ZDBS-LY-DQC010), and the National Natural Science Foundation of China (Grant Nos. 41876012; 41861144015).

\section{REFERENCES}

Ballinger, T. J., and Coauthors, 2020: Surface air temperature. Arctic Report Card: Update for 2020, https: //doi.org/10.25923/ gcw8-2z06.

Behringer, D., and Y. Xue, 2004: Evaluation of the global ocean data assimilation system at NCEP: The Pacific Ocean. Eighth Symposium on Integrated Observing and Assimilation Systems for Atmosphere, Oceans, and Land Surface, AMS 84th Annual Meeting, Washington State Convention and Trade Center, Seattle, Washington, Amer. Meteor. Soc.

Chen, W., X. Q. Lan, L. Wang, and Y. Ma, 2013: The combined effects of the ENSO and the Arctic Oscillation on the winter climate anomalies in East Asia. Chinese Science Bulletin, 58(12), 1355-1362, https://doi.org/10.1007/s11434-012-5654-5.

Cohen, J. L., and Coauthors, 2020: Divergent consensuses on Arctic amplification influence on midlatitude severe winter weather. Nature Climate Change, 10, 20-29, https://doi.org/10.1038/s41558-019-0662-y.

Cohen, J. L., and Coauthors, 2014: Recent Arctic amplification and extreme mid-latitude weather. Nature Geoscience, 7(9), 627-637, https://doi.org/10.1038/ngeo2234. 
Ding, Y. H., Z. Y. Wang, Y. F. Song, and J. Zhang, 2008: Causes of the unprecedented freezing disaster in January 2008 and its possible association with the global warming. Acta Meteorological Sinica, 66, 808-825, https://doi.org/10.3321/j.issn:0577-6619. 2008.05.014.

Gao, H., 2009: China's snow disaster in 2008, who is the principal player? International Journal of Climatology, 29, 2191-2196, https:/ /doi.org/10.1002/joc.1859.

Hu, Z. Z., A. Kumar, Y. Xue, and B. Jha, 2014: Why were some La Niñas followed by another La Niña? Climate Dyn, 42, 1029-1042, https://doi.org/10.1007/s00382-013-1917-3.

Huang, B. Y., and Coauthors, 2017a: Extended Reconstructed Sea Surface Temperature, version 5 (ERSSTv5): Upgrades, validations, and intercomparisons. J. Climate, 30, 8179-8205, https://doi.org/10.1175/JCLI-D-16-0836.1.

Huang, J. B., and Coauthors, 2017b: Recently amplified arctic warming has contributed to a continual global warming trend. Nature Climate Change, 7, 875-879, https://doi.org/10.1038/s41558-017-0009-5.

Huang, R. H., and W. Chen, 2002: Recent progresses in the research on the interaction between Asian monsoon and ENSO cycle. Climatic and Environmental Research, 7(2), 146-159, https://doi.org/10.3969/j.issn.1006-9585.2002.02.003. (in Chinese with English abstract)

Li, J. P., F. Zheng, C. Sun, J. Feng, and J. Wang, 2019: Pathways of influence of the northern hemisphere mid-high latitudes on East Asian climate: A review. Adv. Atmos. Sci., 36, 902-921, https://doi.org/10.1007/s00376-019-8236-5.

Liu, Y. Q., and Y. H. Ding, 1992: Influence of ENSO events on weather and climate of China. Quarterly Journal of Applied Meteorology, 3(4), 473-481. (in Chinese with English abstract)

Manabe, S., and R. T. Wetherald, 1975: The effects of doubling the $\mathrm{CO}_{2}$ concentration on the climate of a general circulation model. $J$. Atmos. Sci., 32(1), 3-15, https://doi.org/10.1175/1520-0469(1975)032<0003:TEODTC >2.0.CO;2.

Maykut, G. A., 1982: Large-scale heat exchange and ice production in the central Arctic. J. Geophys. Res. Oceans, 87, 7971-7984, https://doi.org/10.1029/JC087iC10p07971.

Taylor, P. C., B. M. Hegyi, R. C. Boeke, and L. N. Boisvert, 2018: On the increasing importance of air-sea exchanges in a thawing Arctic: A review. Atmosphere, 9(2), 41, https://doi.org/10.3390/atmos9020041.

Wang, Z. Y., Y. H. Ding, B. T. Zhou, and L. J. Chen, 2020: Comparison of two severe low-temperature snowstorm and ice freezing events in China: Role of Eurasian mid-high latitude circulation patterns. International Journal of Climatology, 40(7), 3436-3450, https://doi.org/10.1002/joc.6406.

Wu, B. Y., and J. Wang, 2002: Winter Arctic Oscillation, Siberian high and East Asian winter monsoon. Geophys. Res. Lett., 29, 1897, https://doi.org/10.1029/2002GL015373.

Wu, B. Y., J. Z. Su, and R. H. Zhang, 2011a: Effects of autumn-winter arctic sea ice on winter Siberian high. Chinese Science Bulletin, 56, 3220-3228, https://doi.org/10.1007/s11434-011-4696-4.

Wu, B. Y., K. Yang, and J. A. Francis, 2016: Summer Arctic dipole wind pattern affects the winter Siberian High. International Journal of Climatology, 36, 4187-4201, https://doi.org/10.1002/joc.4623.

Wu, Z. W., J. P. Li, Z. H. Jiang, and J. H. He, 2011b: Predictable climate dynamics of abnormal East Asian winter monsoon: Once-in-acentury snowstorms in 2007/2008 winter. Climate Dyn., 37, 1661-1669, https://doi.org/10.1007/s00382-010-0938-4.

Yang, S., K. M. Lau, and K. M. Kim, 2002: Variations of the East Asian jet stream and Asian-Pacific-American winter climate anomalies. J. Climate, 15(3), 306-325, https://doi.org/10.1175/1520-0442(2002)015<0306:VOTEAJ>2.0.CO;2.

Yuan, Y., and H. M. Yan, 2013: Different types of La Niña events and different responses of the tropical atmosphere. Chinese Science Bulletin, 58, 406-415, https://doi.org/10.1007/s11434-012-5423-5.

Yuan, Y., C. Y. Li, and S. Yang, 2014: Decadal anomalies of winter precipitation over southern China in association with El Nino and La Niña. J. Meteor. Res., 28(1), 91-110, https://doi.org/10.1007/s13351-014-0106-6.

Zhang, Q. Y., S. L. Xuan, and J. B. Peng, 2008: Relationship between Asian circulation in the middle-high latitude and snowfall over South China during La Niña events. Climatic and Environmental Research, 13(4), 385-394, https://doi.org/10.3878/j.issn.10069585.2008.04.04. (in Chinese with English abstract)

Zheng, F., and J. Zhu, 2010: Coupled assimilation for an intermediated coupled ENSO prediction model. Ocean Dynamics, 60(5), 1061-1073, https://doi.org/10.1007/s10236-010-0307-1.

Zheng, F., and J. Zhu, 2016: Improved ensemble-mean forecasting of ENSO events by a zero-mean stochastic error model of an intermediate coupled model. Climate Dyn., 47(12), 3901-3915, https://doi.org/10.1007/s00382-016-3048-0.

Zheng, F., and J. Y. Yu, 2017: Contrasting the skills and biases of deterministic predictions for the two types of El Niño. Adv. Atmos. Sci., 34(12), 1395-1403, https://doi.org/10.1007/s00376-017-6324-y.

Zheng, F., J. Zhu, R. H. Zhang, and G. Q. Zhou, 2006: Ensemble hindcasts of SST anomalies in the tropical Pacific using an intermediate coupled model. Geophys. Res. Lett., 331(19), L19604, https://doi.org/10.1029/2006GL026994.

Zheng, F., J. Zhu, and R. H. Zhang, 2007: Impact of altimetry data on ENSO ensemble initializations and predictions. Geophys. Res. Lett., 34(13), L13611, https://doi.org/10.1029/2007GL030451.

Zheng, F., J. Zhu, H. Wang, and R. H. Zhang, 2009: Ensemble hindcasts of ENSO events over the past 120 years using a large number of ensembles. Adv. Atmos. Sci., 26(2), 359-372, https://doi.org/10.1007/s00376-009-0359-7.

Zheng, F., L. S. Feng, and J. Zhu, 2015: An incursion of off-equatorial subsurface cold water and its role in triggering the "double dip" La Niña event of 2011. Adv. Atmos. Sci., 32(6), 731-742, https://doi.org/10.1007/s00376-014-4080-9. 